\title{
Effect of national culture on BMI: a multilevel analysis of 53 countries
}

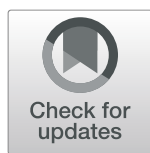

Mohd Masood $^{1,2,3^{*}}$ (D), Akash Aggarwal ${ }^{1}$ and Daniel D. Reidpath ${ }^{3}$

\begin{abstract}
Background: To investigate the association between national culture and national BMI in 53 low-middle- and highincome countries.

Methods: Data from World Health Survey conducted in 2002-2004 in low-middle- and high-income countries were used. Participants aged 18 years and over were selected using multistage, stratified cluster sampling. BMI was used as an outcome variable. Culture of the countries was measured using Hofstede's cultural dimensions: Uncertainty avoidance, individualism, Power Distance and masculinity. The potential determinants of individual-level BMI were participants' sex, age, marital status, education, occupation as well as householdwealth and location (rural/urban) at the individual-level. The country-level factors used were average national income (GNI-PPP), income inequality (Gini-index) and Hofstede's cultural dimensions. A two-level randomintercepts and fixed-slopes model structure with individuals nested within countries were fitted, treating BMI as a continuous outcome variable.

Results: A sample of 156,192 people from 53 countries was included in this analysis. The design-based (weighted) mean BMI (SE) in these 53 countries was 23.95(0.08). Uncertainty avoidance (UAI) and individualism (IDV) were significantly associated with BMI, showing that people in more individualistic or high uncertainty avoidance countries had higher BMI than collectivist or low uncertainty avoidance ones. This model explained that one unit increase in UAI or IDV was associated with 0.03 unit increase in BMI. Power distance and masculinity were not associated with BMI of the people. National level Income was also significantly associated with individual-level BMI.

Conclusion: National culture has a substantial association with BMI of the individuals in the country. This association is important for understanding the pattern of obesity or overweight across different cultures and countries. It is also important to recognise the importance of the association of culture and BMI in developing public health interventions to reduce obesity or overweight.
\end{abstract}

Keywords: Obesity, BMI, Culture

\section{Background}

Globally in 2010, obesity accounted for approximately 3.4 million deaths, $3.9 \%$ of years of life lost, and $3.8 \%$ of disability-adjusted life-years $[1,2]$. Outside the clinical and bench sciences, obesity-related research has mostly focussed on identifying individual-level and neighbourhood level factors that could explain the

\footnotetext{
* Correspondence: M.Masood@latrobe.edu.au

${ }^{1}$ Department of Dentistry and Oral Health, La Trobe Rural Health School, La

Trobe University, Bendigo, Australia

${ }^{2}$ Division of Population and Patient Health, Dental Institute, King's College

London, London, UK

Full list of author information is available at the end of the article
}

trends in increasing BMI observable around the world [3]. Little research has been conducted to identify country-level factors for the variation in BMI and that too mainly focussed on national income [4]. If variation in BMI levels across the countries can be associated with national income, it may also be associated with national cultural factors.

"Culture" has a myriad definition which is hotly contested within anthropology, and between anthropology and other disciplines [5]. One common set of definitions

(c) The Author(s). 2019 Open Access This article is distributed under the terms of the Creative Commons Attribution 4.0 International License (http://creativecommons.org/licenses/by/4.0/), which permits unrestricted use, distribution, and reproduction in any medium, provided you give appropriate credit to the original author(s) and the source, provide a link to the Creative Commons license, and indicate if changes were made. The Creative Commons Public Domain Dedication waiver (http://creativecommons.org/publicdomain/zero/1.0/) applies to the data made available in this article, unless otherwise stated. 
relate to shared beliefs, norms, and values transmitted across generations [6]. In Social Causes of Health and Disease, William Cockerham defined culture as: ways of living that have been passed on from one generation to the next in the form of abstract ideas, norms, habits, customs, and in the creation of material objects such as food, dress, housing etc. Culture thus refers to a body of common understandings that represent what groups of people and societies think, feel, and act upon. The knowledge, beliefs, values, customs, and behaviours shared by people in a particular society reflect the culture of that society [7].

Culture affects the circumstances in which we eat, the type of food we eat, with whom we eat it, the times of day we eat it, and the quantities we eat. Our dietary choices are patterned by biology, psychology, and economics. These choices reflect our cultures and our cultural identities [8]. Sociological and marketing studies underline how food represents an everyday materialization of ethnic identity, and resistance to make a change in food choices [9]. We would suggest that eating is culturally patterned, and by extension secular changes in population, adiposity will be influenced inter alia by the shared national culture of a population.

One challenge in attempting to explore culturally bound influences and their effect on obesity risk is the complexity inherent in measuring factors such as cultural values and beliefs [10]. For this reason, it is required to have quantifiable metrics for the culture that can provide comparable values for different cultures or societies or countries. Hofstede empirically developed a metric to measure national culture using four dimensions of countries' culture. These dimensions are extensively validated against other aspects of national societies and for their cross-time stability [11]. It is the most comprehensive and robust framework in terms of the number of national cultures samples [12, 13]. Consequently, Hofstede's operationalization of cultures (1984) is frequently used in research studies [14-17]. The aim of this study is to investigate the relationship between national culture using a valid national culture metric and body mass index.

\section{Methods}

Data from the World Health Survey (WHS) conducted in 2002-2004 by the World Health Organization (WHO) in 70 countries was used in this study. The WHS was conducted for gathering valid, reliable and comparable information on health status and health system from low, middle and high-income countries. Adults aged $\geq 18$ years living in private households in each nation were the target population for each nation.
The target population, in each country, was adults aged $\geq 18$ years living in private households. With the intentions of collecting nationally representative samples, multistage stratified cluster sampling was used to select participants. This project was approved by the Monash University Human Research Ethics Committee (MUHREC), Project Number: CF14/3907-2,014,002,034.

Individual-level BMI was estimated by using height and weight reported by the participant. Potential determinants of individual-level BMI considered in the analysis comprised various individual and countrylevel factors. Individual-level factors included: sex, age, marital status, education, occupation, economic status and location of household. These individuallevel factors were selected based on the previous well established evidence for association of demographic factors like sex, age and marital status with BMI [2, 18-20]. Similarly, socioeconomic factors including education, occupation and economic status have been reported to influence both intake and expenditure of energy [19, 21]. Evidence for the location of household, rural or urban, and obesity is quite consistent as the prevalence of obesity in urban and rural areas has been reported to be higher in low and middleincome countries, and high-income countries, respectively [22-24]. Age was measured in years. Marital status could be married (including those living together), never married or formerly married (split, divorced or widowed). Educational status was classified into three levels: $\leq$ primary school, secondary school/college, or higher. A wealth index classifying households based on their occupancy of a range of household assets was used to determine the economic status of a household [25]. The household items included in the index were: the number of rooms, cars, chairs and tables in the house; the presence of electricity, bicycle, bucket, washing machine, dishwasher, refrigerator, fixed line telephone, mobile/cellular telephone, television, computer and clock [25]. Country-specific items according to living standards of the country were also included, and the final list comprised 11-20 items. Index of the asset variables for each country was then created based on the weights determined by principal component analysis (PCA). A continuous index measure was obtained by applying the weights of the first component to each individual's data [25]. PCA score was then divided into five parts to define wealth quintiles as Quintile 1(poorest), Quintile 2 (lower-middle), Quintile 3 (middle), Quintile 4 (higher-middle), and Quintile 5 (wealthiest). Occupation was categorized following the Goldthorpe schema [26]: High (Legislator, Manager, Senior official, Professional and Armed Forces), medium (Technician, Associate Professional, Clerk, Service or sales worker), low (Agricultural, fishery worker, 
Craft, trades worker, Plant/machine operator or assembler) and elementary (elementary workers).

Country-level factors were average national income and income inequality as they have been most commonly used country-level economic factors in relation to health and obesity. National income was measured as GNI-PPP (centred at the mean of USD 8840) for the year 2003 [27]. Income inequality was determined using the Gini index, which varies from 0 (perfect equality) to 100 (perfect inequality) $[28,29]$. Data on GNI-PPP and Gini index were obtained from the World Bank [27, 30].

National culture was measured using Hofstede's cultural dimensions: Uncertainty avoidance (UAI), individualism (IDV), Power Distance (PDI) and masculinity (MAS). Data on these cultural dimensions was obtained from Hofstede's book "Cultural Consequences", 2nd edition [31]. Uncertainty Avoidance Index, Individualism index, Power distance index, and Masculinity versus Femininity Index from Hofstede et al. (2010) were referred for UAI, IDV, PDI and MAS scores, respectively [31]. These indices refer to relative differences between countries and scores varied between 0 and 100. Data on IDV, PDI, MAS and UAI was available only for 53 WHS countries. This paper analysed the relationship between national culture and BMI independent of physical activity.

Population estimates and standard errors for each country were generated using sampling weights to account for the stratification and clustering in the survey design. R-3.1.0 with the "survey package" was used for all design-based analyses and the lme4 package was used for multilevel linear regression analysis. A paper fitting the interaction term between individual level and country-level variables has been published previously [32].

In this study, we treated BMI as a continuous variable, and fitted a two-level random intercept and fixed-slopes model with individuals listed within countries. The full maximum likelihood method in $\mathrm{R}$ was applied to determine the fixed- and randomparameter estimates for the two-level regression model. Multilevel modelling incorporating survey design features are under continuous debate and are not currently available in $\mathrm{R}$, therefore results from multilevel modelling were not weighted [33]. We first estimated the null model (model 0 ) and then gradually added explanatory variables into the model. All individual-level factors and GNI-PPP and Gini index were included as explanatory variables in Model 1 . Cultural dimensions were subsequently added in the following models (model 2-model 5). In model 6, all the 3 significant dimensions were added together in the multivariate analysis to see the effect of all the cultural dimensions together.

\section{Results}

A sample of 156,192 people from 53 countries was included in this analysis (Table 1). The design-based (weighted) mean BMI (SE) in these 53 countries was 23.95(0.08) and the design-based (weighted) mean age (SE) of the sample from these 53 countries was 41.27(0.19) (Table 2). The pattern of mean BMI in 53 countries is presented in Fig. 1. The lower and higher end of the BMI were predominated by low-income countries and high or middle-income countries, respectively. Swaziland was an exception as a low-income country with a high BMI.

Results of multilevel models for BMI and countrylevel and individual-level variables are presented in Table 3. First, we ran the null model or the variance component model for 53 countries. The fixed part is represented by the coefficient for the constant, which is 24.60 with a standard error of 0.25 . That is to say, the estimated overall population mean for BMI is 24.60 for 53 countries. The random part is given under the heading "Random effect" for the variance of level 1 residuals and "variance and covariance of random effects" for the variance of the random intercept. Accordingly, the estimate of the betweencountries variance is $2.82(\mathrm{SD}=1.68)$ and the estimate of within country variance is $20.41 \quad(\mathrm{SD}=4.52)$. A total of $12.0 \%$ of variance of BMI can be explained by the variations in the characteristics of countries as suggested by the intra-class correlation (proportion of total variance occurring between countries) of 0.12 for BMI in these countries.

In Model 1 the combined effect of all individuallevel variables, GNI-PPP and Gini were tested on BMI (Table 3). There was a positive association between age and BMI, 0.34 units increase in BMI for every 10 years increase in age. However, there was no significant association between gender and BMI. On average people with primary education had lower BMI than those with secondary education. BMI for the married group was significantly higher as compared to never married and previously married groups. A significant association between household wealth and BMI was also found. All wealthier quintiles had higher BMI than the lowest quintile when the rest of the variables are kept constant. Occupation variable showed that BMIs for professionals and elementary workers were not significantly different. However, the mean BMI for people with low occupation was significantly lower than that for professionals. Similarly, mean BMI for people living in rural areas was significantly lower than people living in urban areas. GNI-PPP $(\beta=0.51, p<0.001)$ was positively related but the Gini index did not have any relationship with BMI. 
Table 1 Initial and final sample size after excluding values on height, weight and BMI variables

\begin{tabular}{|c|c|c|c|}
\hline & $\begin{array}{l}\text { Participants } \\
\text { surveyed }\end{array}$ & $\begin{array}{l}\text { Participants } \\
\text { included } \\
\text { in analysis }\end{array}$ & Response rate \\
\hline Australia & 3600 & 2915 & 81.0 \\
\hline Austria & 1055 & 948 & 89.9 \\
\hline Bangladesh & 5552 & 856 & 15.4 \\
\hline Belgium & 1012 & 956 & 94.5 \\
\hline Brazil & 5000 & 4443 & 88.9 \\
\hline Burkina Faso & 4825 & 1725 & 35.8 \\
\hline China & 3993 & 3983 & 99.7 \\
\hline Croatia & 990 & 980 & 99.0 \\
\hline Czech Republic & 935 & 913 & 97.6 \\
\hline Denmark & 1003 & 974 & 97.1 \\
\hline Dominican Republic & 4534 & 3111 & 68.6 \\
\hline Ecuador & 4660 & 4060 & 87.1 \\
\hline Estonia & 1012 & 998 & 98.6 \\
\hline Ethiopia & 4938 & 971 & 19.7 \\
\hline Finland & 1013 & 1004 & 99.1 \\
\hline France & 1008 & 951 & 94.3 \\
\hline Germany & 1259 & 1180 & 93.7 \\
\hline Ghana & 3938 & 3674 & 93.3 \\
\hline Greece & 1000 & 961 & 96.1 \\
\hline Guatemala & 4770 & 3193 & 66.9 \\
\hline Hungary & 1419 & 1399 & 98.6 \\
\hline India & 9994 & 9268 & 92.7 \\
\hline Ireland & 1014 & 910 & 89.7 \\
\hline Israel & 1236 & 1185 & 95.9 \\
\hline Italy & 1000 & 958 & 95.8 \\
\hline Kenya & 4417 & 4288 & 97.1 \\
\hline Latvia & 856 & 735 & 85.9 \\
\hline Luxembourg & 700 & 692 & 98.9 \\
\hline Malawi & 5306 & 5185 & 97.7 \\
\hline Malaysia & 6040 & 4989 & 82.6 \\
\hline Mexico & 38,746 & 23,480 & 60.6 \\
\hline Morocco & 5000 & 2041 & 40.8 \\
\hline Myanmar & 5886 & 5881 & 99.9 \\
\hline Namibia & 4250 & 3766 & 88.6 \\
\hline Nepal & 8688 & 3166 & 36.4 \\
\hline Netherlands & 1091 & 1085 & 99.5 \\
\hline Norway & 984 & 958 & 97.4 \\
\hline Pakistan & 6379 & 3449 & 54.1 \\
\hline Philippines & 10,078 & 8149 & 80.9 \\
\hline Portugal & 1030 & 896 & 87.0 \\
\hline Russian Federation & 4422 & 3501 & 79.2 \\
\hline Senegal & 3226 & 1681 & 52.1 \\
\hline
\end{tabular}

Table 1 Initial and final sample size after excluding values on height, weight and BMI variables (Continued)

\begin{tabular}{llll}
\hline & $\begin{array}{l}\text { Participants } \\
\text { surveyed }\end{array}$ & $\begin{array}{l}\text { Participants } \\
\text { included } \\
\text { in analysis }\end{array}$ & Response rate \\
\hline Slovak Republic & 2519 & 1793 & 71.2 \\
Slovenia & 585 & 571 & 97.6 \\
South Africa & 2352 & 1460 & 62.1 \\
Spain & 6364 & 6161 & 96.8 \\
Sri Lanka & 6732 & 5663 & 84.1 \\
Sweden & 1000 & 975 & 97.5 \\
Turkey & 11,220 & 8149 & 72.6 \\
United Arab Emirates & 1180 & 1132 & 95.9 \\
United Kingdom & 1200 & 1059 & 88.3 \\
Uruguay & 2991 & 2965 & 99.1 \\
Vietnam & 3492 & 3475 & 99.5 \\
Zambia & 3812 & 2212 & 58.0 \\
\hline
\end{tabular}

${ }^{a}$ Response rate after excluding missing and invalid values for height, weight and BMI

In following models, four cultural dimensions were added one by one to see independent effect of each dimension. UAI $(\beta=0.03, \mathrm{p}<0.001)$ was significantly associated with BMI (model 3). IDV $(\beta=0.03, p<$ 0.001 ) was also significantly associated, showing that people are heavier in more individualistic countries than less individualistic (collectivist) ones. In this model, regression coefficient for Gini index becomes significant $(\beta=0.07, p<0.05)$. PDI was also significantly associated with BMI, each unit increase in PDI was associated with 0.02 unit decrease in BMI. MAS was not significantly related to BMI.

In final model Table 4, all the 3 significant dimensions were added together in the multivariate analysis to see the effect of all the cultural dimensions together. This model explained that one unit increase in UAI or IDV was associated with 0.03 unit increase in BMI. However, the effect of PDI on BMI disappeared in this model. It means that the PDI in a country does not have any effect on an individual's BMI after considering the country's UAI and PDI. Relationship of Gini index $(\beta=0.06, p<0.01)$ with BMI got stronger in this model after considering cultural dimensions. This final model explained $61.7 \%$ of country-level and $11.0 \%$ total variance in BMI.

\section{Discussion}

This study found that UAI and IDV had a significant positive association with BMI in 53 WHS countries after controlling for other cultural dimensions, national income, income inequality and individual-level factors. People from high individualistic or high uncertainty avoidance countries had higher BMI compared with 
Table 2 Model based and design-based descriptive analysis of outcome variable (BMI) and individual-level explanatory variables in 53 countries

\begin{tabular}{|c|c|c|}
\hline & Model Based & Design-based \\
\hline & $n=156,192$ & $N=770,151,380$ \\
\hline & Mean \pm SD & Mean \pm SE \\
\hline \multicolumn{3}{|l|}{ Outcome variable } \\
\hline BMI & $24.05(4.92)$ & $23.95(0.08)$ \\
\hline \multicolumn{3}{|l|}{ Explanatory Variables } \\
\hline \multirow[t]{2}{*}{ Age } & $42.33(16.71)$ & $41.27(0.19)$ \\
\hline & $n(\%)$ & $N(\%)$ \\
\hline \multicolumn{3}{|l|}{ Gender } \\
\hline Female & $71,876(53.9)$ & $3,861,707(50.2)$ \\
\hline Male & $61,389(46.06)$ & $3,839,769(49.8)$ \\
\hline Missing values & $5(0.003)$ & $3802(0.0)$ \\
\hline \multicolumn{3}{|l|}{ Education } \\
\hline Primary school & $53,122(39.86)$ & $351,559,014(45.6)$ \\
\hline Secondary school & $64,018(48.08)$ & $304,854,666(39.6)$ \\
\hline College and above & $15,041(11.28)$ & $109,509,803(14.2)$ \\
\hline Missing values & $1026(0.76)$ & $4,227,898(0.5)$ \\
\hline \multicolumn{3}{|l|}{ Marital Statust } \\
\hline Never Married & $24,270(18.21)$ & $156,329,916(20.3)$ \\
\hline Married & $74,971(56.25)$ & $459,772,891(59.7)$ \\
\hline Widowed/Divorced & $25,499(19.13)$ & $122,482,578(15.9)$ \\
\hline Missing values & $8530(6.4)$ & $31,565,995(4.1)$ \\
\hline \multicolumn{3}{|l|}{ Household Income } \\
\hline 1st Quintile (Poorest) & $26,030(19.53)$ & $155,540,304(20.2)$ \\
\hline 2nd Quintile & $26,196(19.65)$ & $151,537,449(19.7)$ \\
\hline 3rd Quintile & $24,542(18.41)$ & $137,002,987(17.8)$ \\
\hline 4th Quintile & $24,592(18.45)$ & $140,199,329(18.2)$ \\
\hline 5th Quintile (Wealthiest) & $24,267(18.20)$ & $12,525,755,316.3)$ \\
\hline Missing values & $7643(5.73)$ & $60,613,759(7.9)$ \\
\hline \multicolumn{3}{|l|}{ Occupation $\neq$} \\
\hline High & $10,090(7.57)$ & $56,431,105(7.3)$ \\
\hline Medium & $18,797(14.10)$ & $106,090,097(13.8)$ \\
\hline Low & $31,012(23.27)$ & $212,328,723(27.6)$ \\
\hline Elementary & $6658(4.99)$ & $39,368,661(5.1)$ \\
\hline Missing values & $66,713(50.05)$ & $355,932,795(46.2)$ \\
\hline \multicolumn{3}{|l|}{ Setting $¥$} \\
\hline Urban & $75,102(56.35)$ & $355,475,737(46.2)$ \\
\hline Rural & $52,265(39.21)$ & $386,726,171(50.2)$ \\
\hline Missing values & $5903(4.42)$ & $27,949,472(3.6)$ \\
\hline
\end{tabular}

†All data in this variable was missing for Turkey; $¥$ All data in this variable was missing for Turkey and Norway; $¥$ All data in this variable was missing for Australia, Netherlands, Norway and Slovenia; Design-based- probability of selection design weights; N-target population; SD- Standard Deviation; SEStandard Error; BMI- Body Mass Index. ${ }^{\psi}$ Occupation categories: High (Legislator, Senior Official, or Manager, Professional and Armed Forces), Middle (Technician or Associate Professional, Clerk, Service or Sales Worker), Low (Agricultural or fishery worker, Craft or Trades Worker, Plant/machine Operator or Assembler), and Elementary (Elementary Workers) people from low individualistic or low uncertainty avoidance countries. This observed association warrants the exploration of the differences in the characteristics of low and high individualistic or uncertainty avoidance countries. Following some possible characteristics of such countries are discussed to explore this observed association.

In high uncertainty avoidance cultures, it is expected that individuals engage in careful planning to reduce risks by attempting to control future events $[34,35]$. In this scenario, it is expected that the people from high uncertainty avoidance countries should have planned for the uncertainty related to obesity and related health outcomes and should have more strict rules and regulations related to those issues to prevent or reduce it. This argument indicates a negative association between uncertainty avoidance and BMI but results in this study showed a reverse pattern. There are a few reasons for this reverse pattern of high BMI in high uncertainty avoidance, countries. Paradoxically, in countries with weak uncertainty avoidance where rules are less sacred, they are often better followed. However, in countries with strong uncertainty avoidance, laws can fulfil a need for security, even when they are not followed [28]. Additionally, these high uncertainty avoidance countries usually plan for future ambiguous situations related to obesity, mainly by planning for curative treatment with more specialists and utilization of more medicine $[17,36]$. Tolerance to familiar risks has been reported to be very high in UAI countries $[37,38]$. As obesity and overweight are encountered on a regular basis, tolerance to familiar risk activities which predispose to these problems is likely to be high. It is more challenging to instil ownership of obesity prevention when the problem is regarded as a countrywide issue, rather than a country in which relatively less percentage of the population has obesity. In such situations, there is a greater likelihood of non-compliance of key preventive strategies and interventions, such as physical activity, which require extra effort or time [39]. Moreover, once a behaviour, healthy or unhealthy, is adopted it is difficult to use new policies to change this behaviour due to instinctive resistance to change [40]. In cultures with high UAI, people expect health professionals or the government to provide solutions for the problems and expect that the experts always have a solution [41, 42]. This leads to a more curative rather preventive attitude in people towards obesity [43]. It is expected that people are likely to find difficulty in accepting a recommendation to prevent or manage obesity simply through healthy diet management and more physical activities. Public health approaches to prevent or 


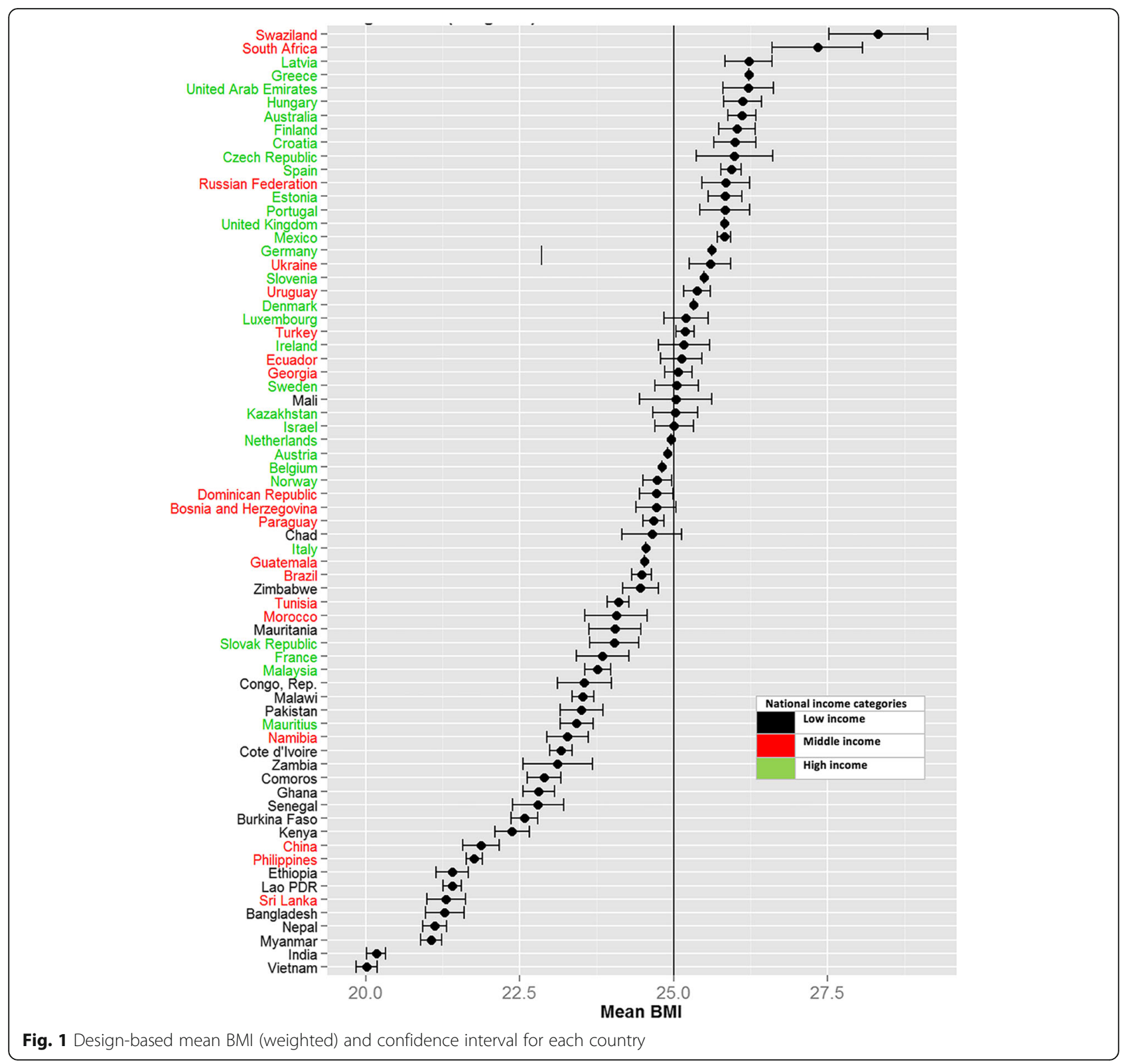

control obesity in a country must consider its' UAI dimension. The clarity in the message or in the content is strongly desired in high UAI countries [37]. High level verbal specificity is required to maintain the sense of security in one's beliefs, and communication that includes free verbal play with its inevitable risks of misunderstanding should be avoided. To implement a public health policy or programme in a country with higher UAI scores, the proposals should be backed up with facts and statistics to negate uncertainty, it should not be expected that unfamiliar policies, ideas or methods will be readily embraced [44]. Enough time should be allowed to help people to develop an understanding of the initiative to help foster confidence in it; community involvement in projects is desired to develop a sense of understanding, and then decrease the element of the unknown $[36,45]$.

Low IDV (collectivist) societies believe that health is controlled by external sources beyond their control such as the family, society. Cheng et al. (2013) described in a meta-analysis that in collectivist societies decision making and group behaviour are largely determined by the contexts such as society or family [46]. Families tend to eat together, portion sizes are reduced, and snacking behaviour is less frequent [36, 47, 48]. In contrast, members of individualistic societies tend to consider the decision-making and individual behaviour 
Table 3 Multilevel multivariate linear regression analysis with individual and country level predictors in 53 countries

\begin{tabular}{|c|c|c|c|c|c|c|c|c|c|c|}
\hline \multirow{3}{*}{ Fixed Effect } & \multicolumn{2}{|c|}{ Model 1} & \multicolumn{2}{|c|}{ Model 2} & \multicolumn{2}{|c|}{ Model 3} & \multicolumn{2}{|c|}{ Model 4} & \multicolumn{2}{|c|}{ Model 5} \\
\hline & \multirow[t]{2}{*}{$\bar{\beta}$} & \multirow[t]{2}{*}{ SE } & \multirow[t]{2}{*}{$\beta$} & \multirow[t]{2}{*}{ SE } & \multirow[t]{2}{*}{$\beta$} & \multirow[t]{2}{*}{ SE } & \multirow[t]{2}{*}{$\beta$} & \multirow[t]{2}{*}{ SE } & \multirow[t]{2}{*}{$\beta$} & \multirow[t]{2}{*}{ SE } \\
\hline & & & & & & & & & & \\
\hline Intercept & 23.3 & $0.26^{* * *}$ & 23.3 & $0.24^{* * *}$ & 23.5 & $0.26^{* * *}$ & 23.5 & $0.26^{* * *}$ & 23.2 & $0.26^{* * *}$ \\
\hline \multicolumn{11}{|l|}{ Country Level } \\
\hline GNI-PPP/10000 & 0.51 & $0.14^{* * *}$ & 0.44 & $0.13^{* *}$ & 0.41 & $0.13^{* *}$ & 0.45 & $0.13^{* *}$ & 0.51 & $0.13^{* *}$ \\
\hline Gini & 0.05 & 0.03 & 0.03 & 0.02 & 0.07 & $0.02^{* *}$ & 0.06 & $0.02^{*}$ & 0.05 & 0.02 \\
\hline UAl & & & 0.03 & $0.009^{* *}$ & & & & & & \\
\hline IDV & & & & & 0.03 & $0.009^{*}$ & & & & \\
\hline PDI & & & & & & & -0.02 & $0.009^{*}$ & & \\
\hline MAS & & & & & & & & & 0.005 & 0.009 \\
\hline \multicolumn{11}{|l|}{ Individual-level } \\
\hline Age & 0.04 & $0.001^{* * *}$ & 0.04 & $0.001^{* * *}$ & 0.04 & $0.001^{* * *}$ & 0.04 & $0.001^{* * *}$ & 0.04 & $0.001^{* * *}$ \\
\hline \multicolumn{11}{|l|}{ Gender } \\
\hline Female & \multicolumn{2}{|c|}{ Reference category } & & & & & & & & \\
\hline Male & 0.012 & 0.03 & 0.012 & 0.03 & 0.012 & 0.03 & 0.012 & 0.03 & 0.012 & 0.03 \\
\hline \multicolumn{11}{|l|}{ Education } \\
\hline Primary school & Referer & category & & & & & & & & \\
\hline Secondary school & 0.19 & $0.03^{* * *}$ & 0.19 & $0.03^{* * *}$ & 0.19 & $0.03^{* * *}$ & 0.19 & $0.03^{* * *}$ & 0.19 & $0.03^{* * *}$ \\
\hline College and above & -0.11 & $0.05^{*}$ & -0.11 & $0.05^{*}$ & -0.11 & $0.05^{*}$ & -0.11 & $0.05^{*}$ & -0.11 & $0.05^{*}$ \\
\hline Marital Status & & & & & & & & & & \\
\hline Never Married & Referer & category & & & & & & & & \\
\hline Married & 1.16 & $0.04^{* * *}$ & 1.16 & $0.04^{* * *}$ & 1.16 & $0.04^{* * *}$ & 1.16 & $0.04^{* * *}$ & 1.16 & $0.04^{* * *}$ \\
\hline Single & 0.74 & $0.04^{* * *}$ & 0.74 & $0.05^{* * *}$ & 0.74 & $0.05^{* * *}$ & 0.74 & $0.05^{* * *}$ & 0.74 & $0.05^{* * *}$ \\
\hline Household Income & & & & & & & & & & \\
\hline 1st Quintile (Poorest) & Referer & category & & & & & & & & \\
\hline 2nd Quintile & 0.18 & $0.039^{* * *}$ & 0.18 & $0.039^{* * *}$ & 0.18 & $0.039^{* * *}$ & 0.18 & $0.039^{* * *}$ & 0.18 & $0.039^{* * *}$ \\
\hline 3rd Quintile & 0.30 & $0.039^{* * *}$ & 0.30 & $0.039^{* * *}$ & 0.30 & $0.039^{* * *}$ & 0.30 & $0.039^{* * *}$ & 0.30 & $0.039^{* * *}$ \\
\hline 4th Quintile & 0.38 & $0.039 * * *$ & 0.38 & $0.039^{* * *}$ & 0.38 & $0.039^{* * *}$ & 0.38 & $0.039^{* * *}$ & 0.38 & $0.039^{* * *}$ \\
\hline 5th Quintile (Wealthiest) & 0.50 & $0.039^{* * *}$ & 0.50 & $0.039^{* * *}$ & 0.50 & $0.039^{* * *}$ & 0.50 & $0.039^{* * *}$ & 0.50 & $0.039^{* * *}$ \\
\hline Occupation ${ }^{\psi}$ & & & & & & & & & & \\
\hline High & Referer & category & & & & & & & & \\
\hline Middle & -0.043 & 0.057 & -0.043 & 0.057 & -0.043 & 0.057 & -0.04 & 0.057 & -0.043 & 0.057 \\
\hline Low & -0.25 & $0.057^{* * *}$ & -0.25 & $0.057^{* * *}$ & -0.25 & $0.057^{* * *}$ & -0.25 & $0.057^{* * *}$ & -0.25 & $0.057^{* * *}$ \\
\hline Elementary & 0.16 & $0.074^{*}$ & 0.16 & $0.074^{*}$ & 0.16 & $0.074^{*}$ & 0.16 & $0.074^{*}$ & 0.16 & $0.074^{*}$ \\
\hline Setting & & & & & & & & & & \\
\hline Urban & Referer & category & & & & & & & & \\
\hline Rural & -0.36 & $0.03^{* * *}$ & -0.36 & $0.03^{* * *}$ & -0.36 & $0.03^{* * *}$ & -0.36 & $0.03^{* * *}$ & -0.36 & $0.03^{* * *}$ \\
\hline Random effect & & & & & & & & & & \\
\hline Country & 1.8 & 1.34 & 1.5 & 1.23 & 1.54 & 1.23 & 1.62 & 1.27 & 1.77 & 1.33 \\
\hline Residual & 19.60 & 4.41 & 19.60 & 4.43 & 19.60 & 4.43 & 19.60 & 4.43 & 19.60 & 4.43 \\
\hline Fit Indices & & & & & & & & & & \\
\hline $\mathrm{AIC}$ & 775,010 & & 775,00 & & 775,00 & & 775,00 & & 775,01 & \\
\hline $\mathrm{BIC}$ & 775,22 & & 775,22 & & 775,23 & & 775,23 & & 775,23 & \\
\hline Log Likelihood & $-387,4$ & & $-387,4$ & & $-387,4$ & & -387, & & -387, & \\
\hline
\end{tabular}


Table 3 Multilevel multivariate linear regression analysis with individual and country level predictors in 53 countries (Continued)

\begin{tabular}{|c|c|c|c|c|c|c|}
\hline & Model 1 & Model 2 & Model 3 & Model 4 & Model 5 & \\
\hline & SE & SE & SE & SE & $\beta$ & SE \\
\hline Deviance & $774,966.0$ & $774,958.2$ & $774,959.4$ & $774,961.5$ & $774,965.7$ & \\
\hline Model Comparison & With model 0 & With model 10 & With model 12 & & & \\
\hline Chi-sq (df) & $5465.3(19)^{* * *}$ & $10.28(1)^{* *}$ & $6.6(1)^{*}$ & $4.5(1)^{*}$ & $0.30(1)$ & \\
\hline \multicolumn{7}{|l|}{$R^{2}$} \\
\hline Country Level $R^{2}$ & 0.362 & 0.468 & 0.454 & 0.426 & 0.372 & \\
\hline Individual-level $\mathrm{R}^{2}$ & 0.040 & 0.040 & 0.040 & 0.040 & 0.040 & \\
\hline Total R & 0.079 & 0.092 & 0.090 & 0.087 & 0.080 & \\
\hline
\end{tabular}

${ }^{*} p$ value $\leq 0.05 ;{ }^{* *} p$ value $\leq 0.01 ;{ }^{* * *} p$ value $\leq 0.001 ; \beta$ regression coefficient, SE Standard Error, AIC Akaike information criterion, BIC Bayesian information criterion, Chisq Chi Square test, $d f$ Degree of freedom; GNI-PPP/10000- National income; Gini- income inequality; UAI-Uncertainty Avoidance; IDV- Individualism, PDI- Power distance, MAS- Masculinity; ${ }^{4}$ Occupation categories: High(Legislator, Senior Official, or Manager, Professional, and Armed Forces), Middle(Technician or Associate Professional, Clerk, Service or Sales Worker), Low (Agricultural or Fishery Worker, Craft or Trades Worker, Plant/machine Operator or Assembler), and Elementary (Elementary Workers)

to be contingent upon their own actions, under personal control, and relatively independent of the contexts such as society or family. This personal control on the food is associated with higher intake of food, larger portions of food, no one to share with, and more frequent snacking probably due to more snacking opportunities $[49,50]$. For example, in most individualist countries such as the UK and the USA, the concept of 'children's food' has developed. In most other cultures, young children gradually move from a diet of baby food to family food. But in these individualist countries, there are certain types of food (fish fingers, baked beans, chicken nuggets) which are specifically designed and marketed for children [51]. This availability of genre of children food has two consequences. At first, as this is children's food, children have more control over the size of the serving. Secondly, children have become customers in their own right for manufactures selling easy to prepare foods of poor nutritional value which may be in part a contributing factor for increased BMI levels [52].

The motivations for eating and physical activity also vary among different cultures [37]. In a collectivist society, like Japan, physical and environmental motivations are usual triggers for eating. Physical eating is triggered by hunger cues, like growling stomach or the feeling of dizziness. Environmental eating occurs in response to something in the surroundings, such as hearing the lunch bell, smell of food, or check-out stands. People in an individualistic society are triggered to eat, without having specific feelings of hunger or nutritional needs, based on their emotional status and environmental cues such as out of boredom, watching TV or movies [53].

Members of a collectivist society spend more time in role or context dictated activities, which include tending animals, gardening, sleeping, cooking and eating. In contrast, people from individualist societies spend most of their time in idle leisure activities e.g. watching TV, internet and reading papers [36, 54]. For people in individualist societies, lack of motivation is the most commonly reported obstacle to healthy eating and physical activity. For example, residents of an individualistic society such as the USA tend to have high expenditures on amenities which make their lives easier and reduce exercise or effort [50].

Third, the response rate has varied considerably across the countries. However, most of the countries included in this study had good response rates of more than 60\%, except Bangladesh and Ethiopia. Achieving high response rates in national surveys is always challenging, especially for low and middleincome countries. Nonetheless, the results of this study should be interpreted considering the inherent selection bias secondary to exclusion of probability of selection weights from random effects model. Fourth, there are different cut-off values of BMI for obesity and overweight has been suggested based on the different geographic region and ethnicity. These different cut-off points make a multi-country comparison of overweight and obesity more challenging as the country (or ethnic) specific cut-off points for all countries (or ethnic groups) are not available to get correct overweight and obesity prevalence for each country [55]. Therefore, the Body Mass Index (BMI) as a continuous outcome variable is used in this study. Fifth, The WHS data was collected in 2002-2004 and might put uncertainty about the validity of results after 15 years. The main reason for using WHS datasets for this study was that these are unique comparable datasets available for 70 countries representing the countries from a range of low, middle and high-income countries.

\section{Conclusion}

Culture affects the circumstances in which we eat, the types of food we eat, with whom we eat it, the times of 
Table 4 Multilevel multivariate linear regression analysis with individual and country level predictors in 53 countries

\begin{tabular}{|c|c|c|}
\hline & \multicolumn{2}{|l|}{ Model 6} \\
\hline & $\beta$ & SE \\
\hline \multicolumn{3}{|l|}{ Fixed Effect } \\
\hline Intercept & 23.6 & $0.23^{* * *}$ \\
\hline \multicolumn{3}{|l|}{ Country Level } \\
\hline Log GNI-PPP/10000 & 0.30 & $0.14^{*}$ \\
\hline Gini & 0.06 & $0.02^{* *}$ \\
\hline Uncertainty avoidance & 0.03 & $0.008^{* * *}$ \\
\hline Individualism & 0.03 & $0.01^{*}$ \\
\hline Power Distance & -0.01 & 0.009 \\
\hline \multicolumn{3}{|l|}{ Individual-level } \\
\hline Age & 0.04 & $0.001^{* * *}$ \\
\hline \multicolumn{3}{|l|}{ Gender } \\
\hline Female & \multicolumn{2}{|c|}{ Reference category } \\
\hline Male & 0.012 & 0.03 \\
\hline \multicolumn{3}{|l|}{ Education } \\
\hline \multicolumn{3}{|l|}{ Primary school } \\
\hline Secondary school & 0.19 & $0.03^{* * *}$ \\
\hline College and above & -0.11 & $0.05^{*}$ \\
\hline \multicolumn{3}{|l|}{ Marital Status } \\
\hline Never Married & \multicolumn{2}{|c|}{ Reference category } \\
\hline Married & 1.16 & $0.04^{* * *}$ \\
\hline Single & 0.74 & $0.04^{* * *}$ \\
\hline \multicolumn{3}{|l|}{ Household Income } \\
\hline 1st Quintile (Poorest) & \multicolumn{2}{|c|}{ Reference category } \\
\hline 2nd Quintile & 0.18 & $0.039^{* * *}$ \\
\hline 3rd Quintile & 0.30 & $0.039^{* * *}$ \\
\hline 4th Quintile & 0.38 & $0.039^{* * *}$ \\
\hline 5th Quintile (Wealthiest) & 0.50 & $0.039^{* * *}$ \\
\hline \multicolumn{3}{|l|}{ Occupation $^{\psi}$} \\
\hline High & \multicolumn{2}{|c|}{ Reference category } \\
\hline Middle & -0.044 & 0.057 \\
\hline Low & -0.25 & $0.057^{* * *}$ \\
\hline Elementary & 0.16 & $0.074^{*}$ \\
\hline Setting & \multicolumn{2}{|c|}{ Reference category } \\
\hline \multicolumn{3}{|l|}{ Urban } \\
\hline Rural & -0.36 & $0.03^{* * *}$ \\
\hline \multicolumn{3}{|l|}{ Random effect } \\
\hline Country & 1.08 & 1.04 \\
\hline Residual & 19.60 & 4.41 \\
\hline \multicolumn{3}{|l|}{ Fit Indices } \\
\hline $\mathrm{AIC}$ & $774,995.3$ & \\
\hline $\mathrm{BIC}$ & $775,250.1$ & \\
\hline Log Likelihood & $-387,471.7$ & \\
\hline
\end{tabular}

Table 4 Multilevel multivariate linear regression analysis with individual and country level predictors in 53 countries (Continued)

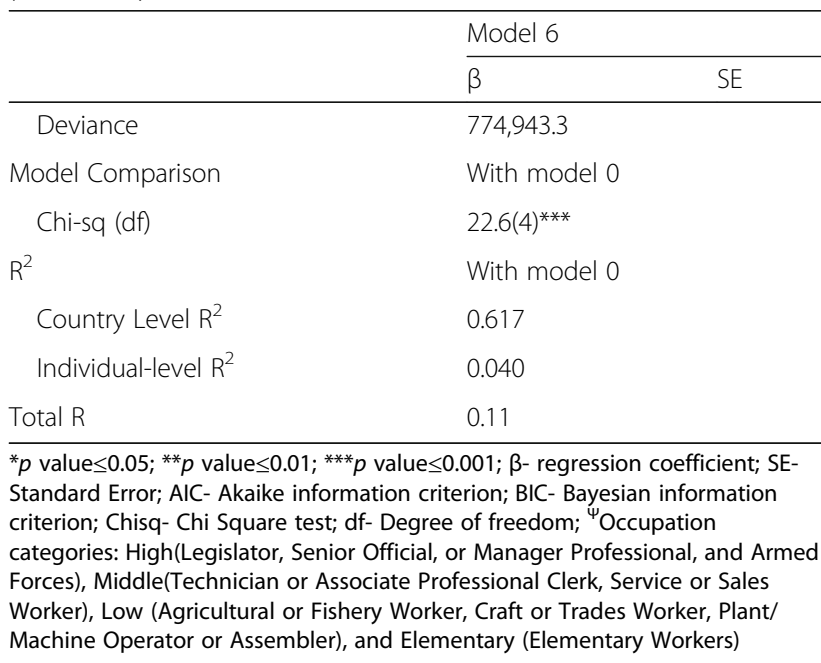

day we eat it, and the quantities we eat. It is important to understand the relationship between culture and BMI. This study showed national culture has a substantial association with BMI of the individuals in the country. Uncertainty-avoidance and individualism national cultural dimensions were significantly associated with BMI, showing that people are heavier in more individualistic or high uncertainty-avoidance countries. This association is important for understanding the pattern of obesity or overweight across different cultures and countries. It is also important to recognise the importance of the association of culture and BMI in developing public health interventions to reduce obesity or overweight.

\section{Acknowledgements}

None.

Authors' contributions

MM contributed in study design, data analysis and writing the paper; DR contributed in study design and writing the paper; AA contributed in writing the paper. All authors have read and approved the manuscript.

\section{Funding}

None.

Availability of data and materials

Data used in this is publicly available and can be accessed from World Health Survey section of the World Health Organization website. http://apps. who.int/healthinfo/systems/surveydata/index.php/catalog/whs

Ethics approval and consent to participate

Ethics approval for this study was provided by Monash University Human Research Ethics Committee (MUHREC), Project Number: CF14/39072014002034

Consent for publication

Not Applicable.

Competing interests

Mohd Masood is Associate Editor of BMC Public Health Journal. 


\section{Author details}

1Department of Dentistry and Oral Health, La Trobe Rural Health School, La Trobe University, Bendigo, Australia. ${ }^{2}$ Division of Population and Patient Health, Dental Institute, King's College London, London, UK. ${ }^{3}$ Department of Global Public Health, Jeffery Cheah School of Medicine and Health Science, Monash University, Bandar Sunway, Malaysia.

Received: 14 April 2019 Accepted: 22 August 2019

Published online: 03 September 2019

\section{References}

1. Ng SW, Zaghloul S, Ali HI, Harrison G, Popkin BM. The prevalence and trends of overweight, obesity and nutrition-related non-communicable diseases in the Arabian Gulf States. Obes Rev. 2011;12(1):1-13.

2. Kanter R, Caballero B. Global gender disparities in obesity: a review. Adv Nutr. 2012;3(4):491

3. Tsai MS, Tsai JH, Liu HW, Chen TP, Chien CH, Liu WJ, et al. Pneumocystis Carinii pneumonia in an AIDS patient with dramatic response to inadvertent steroid therapy--a case report. Gaoxiong Yi Xue Ke Xue Za Zhi. 1989;5(6): 345-9.

4. Lear SA, Teo K, Gasevic D, Zhang X, Poirier PP, Rangarajan S, et al. The association between ownership of common household devices and obesity and diabetes in high, middle and low income countries. CMAJ. 2014;186(4): 258-66.

5. Barnard A, Spencer J. The Routledge encyclopedia of social and cultural anthropology. 2nd ed. London: Routledge; 2010.

6. Plog F, Bates DG. Cultural anthropology. [S.I.]: Knopf; 1976

7. Cockerham WC. Social causes of health and disease. Cambridge: Polity; 2007.

8. Weller DL, Turkon D. Contextualizing the immigrant experience: the role of food and foodways in identity maintenance and formation for first- and second-generation Latinos in Ithaca. New York Ecol Food Nutr. 2015;54(1): 57-73.

9. Cappellini B, Yen D. Little emperors in the UK: acculturation and food over time. J Bus Res. 2013;66(8):968-74.

10. Ulijaszek SJ, Lofink H. Obes Biocultural Perspective. 2006;35(1):337-60.

11. Meeuwesen L, van Den Brink-Muinen A, Hofstede G. Can dimensions of national culture predict cross-national differences in medical communication? Patient Educ Couns. 2009;75(1):58-66.

12. Smith PB. Nations, cultures, and individuals: new perspectives and old dilemmas. J Cross-Cult Psychol. 2004;35(1):6-12.

13. Smith PB, Dugan S, Trompenaars F. National Culture and the values of organizational employees: a dimensional analysis across 43 nations. J CrossCult Psychol. 1996;27(2):231-64.

14. Dawar N, Parker PM, Price LJ JJoibs. A cross-cultural study of interpersonal information exchange 1996;27(3):497-516.

15. Samiee $\mathrm{S}$, Jeong I. Cross-cultural research in advertising: an assessment of methodologies. Official Publication of the Academy of Marketing Science. 1994;22(3):205-17.

16. Wilson $\sqcup$. International consumer behavior: Its impact on marketing strategy development: A. Coskun Samli Westport CT: Quorum Books, 186 pp., \$59.95, 1995 (Book Review). 1997. p. 85-6.

17. Nakata C, Sivakumar K. National Culture and new product development: an integrative review. J Mark. 1996;60(1):61.

18. Thorpe RJ, Ferraro KF. Aging, obesity, and mortality: misplaced concern about obese older people? Rese Aging. 2004;26(1):108.

19. Crawford D, Jeffery RW, Ball K. Obesity epidemiology: from aetiology to public health. USA: Oxford University press; 2010.

20. Sobal J, Rauschenbach BS, Frongillo EA. Marital status, fatness and obesity. Soc Sci Med. 1992;35(7):915-23.

21. Giskes K, van Lenthe FJ, Turrell G, Kamphuis CBM, Brug J, Mackenbach JP. Socioeconomic position at different stages of the life course and its influence on body weight and weight gain in adulthood: a longitudinal study with 13-year follow-up. Obesity. 2008;16(6):1377.

22. Fezeu L, Minkoulou E, Balkau B, Kengne A-P, Awah P, Unwin N, et al. Association between socioeconomic status and adiposity in urban Cameroon. Int J Epidemiol. 2006;35(1):105-11.

23. Wang $Y$, Jahns $L$, Tussing-Humphreys $L$, Xie $B$, Rockett $H$, Liang $H$, et al. Dietary intake patterns of low-income urban African-American adolescents. J Am Diet Assoc. 2010;110(9):1340-5.
24. Yang W, Kanavos P. The less healthy urban population: income-related health inequality in China. BMC Public Health. 2012;12(1):804.

25. Rutstein SO, Johnson K. The DHS wealth index. ORC Macro: Calverton; 2004.

26. Goldthorpe $\mathrm{JH}$, Llewellyn C, Payne C. Social mobility and class structure in modern Britain. 2nd ed. Oxford: Clarendon; 1987.

27. World Bank. GNI per capita, PPP (current international \$) Washington D.C.: World Bank; 2003 [Available from: http://data.worldbank.org/indicator/NY. GNP.PCAP.PP.CD?page $=2$.

28. Cowell FA. Measuring inequality. 2nd ed. London: Prentice Hall/Harvester Wheatsheaf; 1995.

29. Cowell FA. Measuring inequality. 3rd ed. ed. Oxford: Oxford University Press; 2011

30. World Bank. GINI index (World Bank estimate) Washington D.C.: World Bank; 2003 [Available from: http://data.worldbank.org/indicator/SI.POV.GINI?page=2.

31. Hofstede GH, Hofstede GJ, Minkov M. Cultures and organizations : software of the mind : intercultural cooperation and its importance for survival. 3rd ed. New York, London: McGraw-Hill; 2010

32. Masood M, Reidpath D. Effect of national wealth on BMI: an analysis of 206,266 individuals in 70 low-, middle- and high-income countries. PLoS One. 2017:12(6):e0178928.

33. Cai TJ. Investigation of ways to handle sampling weights for multilevel model analyses. Sociol Methodol. 2013;43:178-219.

34. Conduit EJC-cr. Submissiveness and risk of heart disease. 2001;35(4):347-369.

35. de Bellis E, Hildebrand C, Ito K. Herrmann AJML. Cross-national differences in uncertainty avoidance predict the effectiveness of mass customization across East Asia: a large-scale field investigation. 2015;26(3):309-20.

36. Hofstede G. Culture's consequences : comparing values, behaviors, institutions, and organizations across nations. 2nd ed.. ed. Thousand Oaks, Calif. Sage Publications; 2001

37. Hofstede GH. Culture's consequences : comparing values, behaviors, institutions, and organizations across nations. 2nd ed. ed. thousand oaks, calif. ; London: SAGE; 2001.

38. Bailey $H$, Kind P. Preliminary findings of an investigation into the relationship between national culture and EQ-5D value sets. Qual Life Res. 2010;19(8):1145-54.

39. Antoci E, Pinzone MR, Nunnari G, Stefani S, Cacopardo B. Prevalence and molecular characteristics of methicillin-resistant Staphylococcus aureus (MRSA) among subjects working on bovine dairy farms. Le infezioni in medicina : rivista periodica di eziologia, epidemiologia, diagnostica, clinica e terapia delle patologie infettive. 2013;21(2):125-9.

40. Baker D, Carson K. The two faces of uncertainty avoidance:attachment and adaptation. J Behav Appl Manag. 2011;12(2):128-41.

41. Havold JI. National cultures and safety orientation: a study of seafarers working for Norwegian shipping companies. Work Stress. 2007;21(2):173-95.

42. Hofstede G. Dimensionalizing Cultures: The Hofstede Model in Context. Online Readings in Psychology and Culture. 2011;2(1).

43. Veldhuis M. Defensive behavior of Dutch family physicians. Widening the concept. Fam Med. 1994;26(1):27-9.

44. Deschepper R, Grigoryan L, Lundborg CS, Hofstede G, Cohen J, Kelen GV, et al. Are cultural dimensions relevant for explaining cross-national differences in antibiotic use in Europe? BMC Health Serv Res. 2008;8:123.

45. Hofstede GH, Hofstede GJ. Cultures and organizations: software of the mind. New York; London: McGraw-Hill; 2005.

46. Cheng C, Cheung SF, Chio JH, Chan MP. Cultural meaning of perceived control: a meta-analysis of locus of control and psychological symptoms across 18 cultural regions. Psychol Bull. 2013;139(1):152-88.

47. van de Vijver FJR, van Hemert DA, Ype H. Multilevel analysis of individuals and cultures. New York; London: Psychology; 2008.

48. Vartanian LR, Herman CP, Wansink B. Are we aware of the external factors that influence our food intake?(report). Health Psychol. 2008;27(5):533-8.

49. Bergmuller $\mathrm{S}$. The relationship between cultural individualismcollectivism and student aggression across 62 countries. Aggress Behav. 2013:39(3):182-200.

50. Rozin P. The meaning of food in our lives: a cross-cultural perspective on eating and well-being. J Nutr Educ Behav. 2005;37(Suppl 2):S107-12.

51. No E, Kelly B, Devi A, Swinburn B, Vandevijvere S. Food references and marketing in popular magazines for children and adolescents in New Zealand: a content analysis. Appetite. 2014;83:75-81.

52. Martin R. The role of law in the control of obesity in England: looking at the contribution of law to a healthy food culture. Aust New Zealand Health Policy. 2008;5:21.

53. Hawks SR, Madanat HN, Merrill RM, Goudy MB, Miyagawa T. A cross-cultural analysis of 'motivation for eating' as a potential factor in the emergence of 
global obesity: Japan and the United States. Health Promot Int. 2003;18(2): 153-62.

54. Pooye S. Cultural factors leading to overweight and obesity: Cross-cultural analysis of Japan and The United States of America. The Netherlands: Universiteit Van Tilburg; 2010.

55. Tahir AM, Sabaratnam A. Obesity: A Ticking Time Bomb for Reproductive Health. Mahmood TA, Arulkumaran S, editors. Newnes: Elsevier Science; 2012.

\section{Publisher's Note}

Springer Nature remains neutral with regard to jurisdictional claims in published maps and institutional affiliations.

- fast, convenient online submission

- thorough peer review by experienced researchers in your field

- rapid publication on acceptance

- support for research data, including large and complex data types

- gold Open Access which fosters wider collaboration and increased citations

- maximum visibility for your research: over $100 \mathrm{M}$ website views per year

At BMC, research is always in progress. 